\title{
On the Vertical Diffusion from a Ground Level Source in the Atmospheric Boundary Layer
}

\author{
By Tateki Mizuno, Osayuki Yokoyama \\ National Research Institute for Pollution and Resources, Ministry of International Trade \\ and Industry, Tsukuba, Ibaraki 305, Japan \\ and Akira Yasuraoka \\ Research Analysis and Computing Co., Tokyo, Japan \\ (Manuscript received 20 January 1981, in revised form 13 January 1982)
}

\begin{abstract}
Vertical diffusion from a ground level line source was estimated using the structure model of the atmospheric boundary layer proposed by Yokoyama et al. (1977a, b, c). The two-dimensional differential equation of diffusion was computed numerically for stationary and horizontally homogeneous conditions. Making the equation dimensionless, we showed that the characteristic spread $(Z \sigma)$ divided by the height of the boundary layer $(h)$, is a function of two dimensionless lengths, $x / R_{e} h$ and $z_{0} / h$, in the mixing and neutral layers $(x$ : downwind distance from the source, $R_{e}$ : the quantity formed from the characteristic scale of wind speed, eddy diffusivity and the height of the boundary layer, $z_{0}$ : the roughness length of the ground surface.) In the stable layer, another dimensionless length, $h / L$ ( $L$ : Monin-Obukhov length), is needed in addition to the above two parameters.

From the relationship between $Z \sigma / h$ and $x / R_{e} h$, it may be shown that in the mixing layer, $Z \sigma$ is a function of traveling time of the smoke. In the neutral and stable layers, however, $Z_{\sigma}$ is independent of the mean wind speed and depends only on the downwind distance from the source.

As for the computed concentrations, vertical spread $Z \sigma$ in the mixing layer increases rapidly in the early stage of the diffusion and tends to vary slowly when the upper part of the layer affects the diffusion. Profiles of vertical concentration in the mixing layer are nearly exponential when $Z \sigma / h \ll 1$ and approach a Gaussian distribution gradually with an increase in the downwind distance. On the other hand, in the stable layer, these profiles are nearly Gaussian even at short downwind distances and become more rounded at long distances. The estimated vertical spread $Z \sigma$ and concentrations at the ground surface are discussed, comparing them with diffusion experiments and the Pasquill-Gifford chart.
\end{abstract}

\section{Introduction}

Theoretical investigations concerning the diffusion process above the atmospheric surface layer or constant flux layer are generally based on a hypothetical distribution of the exchange coefficient. These investigations were not confirmed by observation of the turbulence above the surface layer. Recently, on the basis of airplane observations performed by Gamo et al. (1976), Yokoyama et al. (1977a, b, c) proposed a structure model of the turbulence in the atmospheric boundary layer. This model was later examined by Gamo and Yokoyama (1979) in the mixing layer and Yamamoto et al. (1979) in the stable layer and appeared to be reasonable for most boundary layers except extremely stable layers. In the extremely stable layer, they suggested that more careful observation be conducted to develop the structure model.

Here, our interest is to show how the diffusion process may be described by their model. As a preliminary study, we considered the vertical diffusion from a ground level source using a Lagrangian similarity method (Yokoyama and Mizuno, 1978). By qualitative analysis, we concluded that in the mixing layer, wind speed does not contribute to the vertical diffusion but merely transports the plume in the downwind direction.

In this paper, a two-dimensional differential 
equation for diffusion from a ground level source will be computed numerically and the characteristics of the vertical profile of the concentration and its dependency on the stratification of the layer will be studied using their structure model.

\section{The equation of diffusion and the model of the atmospheric boundary layer}

The semi-empirical steady state equation for diffusion from a continuous, ground level, line source is given by

$$
U \frac{\partial C}{\partial x}=\frac{\partial}{\partial z}\left(K_{z} \frac{\partial C}{\partial z}\right)+Q
$$

where $C$ is the concentration, $U$ the wind speed, $K_{z}$ the vertical eddy diffusivity and $Q$ the emission strength per unit length. Diffusion in the $x$ direction was neglected compared to the advection term in equation (1). Also, the Coriolis force was ignored since only the vertical diffusion from an infinitely long line source was considered here. The following boundary condition is applied to equation (1) at the ground surface and at the top of the boundary layer.

$$
\frac{\partial C}{\partial z}=0 \quad \text { at } z=0 \text { and } h
$$

We assume that the eddy diffusivity $K_{z}$ is proportional to the eddy diffusivity of momentum $K_{m}$, or $K_{z}=\alpha K_{m}$. Here, $\alpha$ is a dimensionless constant of the order of 1 and should be determined by comparing calculations and experiments. $K_{m}$ is defined as

$$
K_{m}=u_{*}{ }^{2} / \frac{d U}{d z}
$$

where $u_{*}^{2}$ is the momentum flux per unit mass.

Profiles of $\mathrm{U}$ and $K_{m}$ can be obtained from the Monin-Obukhov similarity hypothesis for the surface layer and the model of Yokoyama et al. (loc. cit.) for the upper part of the boundary layer. (i) Mixing layer (free convective layer)

The mixing layer will be divided into two sublayers; the surface layer and the upper layer. In the surface layer, Monin-Obukhov similarity yields

$$
K_{m}(z)=C_{1} w_{*} h\left(\frac{z}{h}\right)^{4 / 3}
$$

where $C_{1}$ is a universal constant and $w_{*}$ is defined by

$$
w_{*}=\left(\frac{g h}{T_{0}} \frac{q_{0}}{C_{p} \rho}\right)^{1 / 3}
$$

where $g$ is the acceleration of gravity, $T_{o}$ the ambient air temperature, $q_{o}$ the latent heat flux, $C_{p}$ the specific heat of air at constant pressure and $\rho$ is the air density. Above the surface layer or in the upper convective layer, Yokoyama et al. (1977a) proposed the eddy diffusivity in the form

$$
K_{m}=C_{1}{ }^{\prime} w_{*} h \Phi(\zeta)
$$

and

$$
\zeta=1-\frac{z}{h}
$$

where $C_{1}{ }^{\prime}$ is a universal constant and $\phi(\zeta)$ is a nondimensional universal function of $\zeta$. According to the observations by Gamo et al. (1976), $\phi(\zeta)$ is approximately given by

$$
\Phi(\zeta) \doteqdot 1
$$

The boundary of the surface layer and the upper convective layer is determined from the height at which $K_{m}$ of the surface layer (4) equals that of the upper layer (6). Putting $C_{1}=0.75$ (Panofsky, 1974) into (4) and $C_{1}{ }^{\prime}=0.034$ (Yokoyama et al., 1977a), we find that the internal boundary height, $h_{o}$, is approximately one-tenth of the whole height of the mixing layer $h$, i.e.,

$$
h_{0} \doteqdot 0.1 h
$$

We assume that from the ground surface to $h_{0}$, $K_{m}$ can be found from (4) and above $h_{o}, K_{m}$ can be found from (5).

The wind profile may be obtained by integrating equation (3)

$$
U=\int_{z_{0}}^{z} \frac{u_{*}^{2}}{K_{m}(z)} d z
$$

where $z_{o}$ is the roughness length of the surface. If $u_{*}$ is assumed to equal the friction velocity at the surface $\left(u_{* 0}\right)$, we have from equations (4) and (10),

$$
U=\frac{3 u_{* 0}{ }^{2}}{C_{1} w_{*}}\left\{\left(\frac{z_{0}}{h}\right)^{-1 / 3}-\left(\frac{z}{h}\right)^{-1 / 3}\right\}
$$

Assuming that $u_{*}$ decreases with height and $d U /$ $d z=0$ at the top of the convective layer, Yokoyama and Yoshikado (1977c) obtained a wind profile of the form

$$
\begin{aligned}
U= & \frac{3 u_{* 0}{ }^{2}}{C_{1} w_{*}}\left[\left(\frac{z_{0}}{h}\right)^{-1 / 3}-\left(\frac{z}{h}\right)^{-1 / 3}\right. \\
& \left.+\frac{1}{2}\left\{\left(\frac{z_{0}}{h}\right)^{2 / 3}-\left(\frac{z}{h}\right)^{2 / 3}\right\}\right]
\end{aligned}
$$

Since the additional term $1 / 2\left\{\left(z_{0} / h\right)^{2 / 3}-(z / h)^{2 / 3}\right\}$ in equation (12) is quite smaller than the term $\left[\left(z_{0} / h\right)^{-1 / 3}-(z / h)^{-1 / 3}\right]$ in equation (11) every where when $z_{o} \ll h$, then the difference between the wind profile equations (11) and (12) is con- 
sidered to have only a small effect on the diffusion process. Therefore, we will choose the wind profile (12) for the following calculations.

(ii) Neutral layer

According to Yokoyama et al. (loc. cit.), the eddy diffusivity in the neutral layer is given by

$$
K_{m}(z)=k u_{* 0} z \zeta
$$

where $k$ is von Karman's constant $(k=0.35$, (Businger et al., 1971). The profile of the wind speed can be obtained by substituting equation (13) into (10);

$$
U=\frac{u_{* 0}}{k}\left(\ln \frac{z}{z_{0}}-\frac{z-z_{0}}{h}\right)
$$

(iii) Stable layer by

The eddy diffusivity in the stable layer is given

$$
K_{m}(z)=\frac{k u_{* 0} z}{1+\beta z / L} \cdot \zeta
$$

where $\beta$ is the universal constant and $L$ the Monin-Obukhov length. If $z \ll h$ or $\zeta \fallingdotseq 1, K_{m}(z)$ tends to the eddy diffusivity in the constant flux layer near the surface, where the value of $\beta$ was estimated experimentally to be about 5 (Webb, 1970; Businger et al., 1971). Thus, we assume that $\beta$ equals 5 in the following calculation.

Substituting (15) into (10) we have

$$
\begin{aligned}
U= & \frac{u_{* 0}}{k}\left[\ln \frac{z}{z_{0}}-\frac{z-z_{0}}{h}+\beta \frac{h}{L} \frac{z-z_{0}}{h}\right. \\
& \left.-\frac{1}{2} \beta \frac{h}{L}\left\{\left(\frac{z}{h}\right)^{2}-\left(\frac{z_{0}}{h}\right)^{2}\right\}\right]
\end{aligned}
$$

\section{Normalization}

Before dealing with equation (1), we will make it dimensionless. Characteristic scales of the variables in equation (1) may be chosen as

$h$ : thickness of the boundary layer

$U_{h}$ : mean wind speed at $z=h$

$K_{m a x}$ : maximum value of the eddy diffusivity $k_{z}$

The following dimensionless quantities will be introduced

$$
\left.\begin{array}{l}
\hat{U}=U / U_{h} \\
\hat{z}=z / h \\
\hat{z}_{0}=z_{0} / h \\
\hat{K}_{z}=K_{z} / K_{\text {max }} \\
\hat{x}=\alpha x /(\text { Reh })
\end{array}\right\}
$$

where $R e$ is defined by

$$
R e=\alpha h \cdot U_{h} / K_{\max }
$$

Dimensionless concentration $C$ will also be introduced as

$$
\hat{C}=C \cdot h \cdot U_{h} / Q
$$

Substituting relationships (17) through (19) into equation (1) we obtain

$$
\hat{U} \cdot \frac{\partial \hat{C}}{\partial \hat{x}}=\frac{\partial}{\partial \hat{z}}\left(\hat{K}_{z} \frac{\partial \hat{C}}{\partial \hat{z}}\right)+1
$$

It appears from equation (20) that $\hat{C}$ must be of the form

$$
\hat{C}=f_{c}\left(\hat{U}, \hat{K}_{z}, \hat{x}, \hat{z}\right)
$$

Figures 1 -a to 1 -c are the profiles of $\hat{U}$ and $\hat{K}_{m}$ in the mixing, neutral and stable layers, respectively. Since $\hat{U}$ depends on $\hat{z}, \hat{z}_{0}$ and $h / L$, and $\hat{K}_{z}$ depends on $\hat{z}$ and $h / L$, equation (21) may be rewritten as

$$
\hat{C}=f_{c}{ }^{\prime}\left(\hat{x}, \hat{z}, \hat{z}_{0}, h / L\right)
$$

where $h / L$ is necessary only for the stable layer. Equation (22) implies that at a distance $\hat{x}$, the vertical distribution of dimensionless concentration $\hat{C}$ is determined by the two parameters $\hat{z}_{0}$ and $h / L$. In other words, if we define the characteristic length $\hat{Z} \sigma(=Z \sigma / h)$ for the vertical spread at $\hat{x}, \hat{Z} \sigma$ should be written in the from

$$
\hat{Z} \sigma=f\left(\hat{x}, \hat{z}_{0}, \frac{h}{L}\right) \equiv f\left(\frac{\alpha x}{\operatorname{Re} h}, \frac{z_{0}}{h}, \frac{h}{L}\right)
$$

Here, the first term of the right-hand side of equation (23) represents the dependency of $\hat{Z}_{\sigma}$ on the normalized downwind distance. The other terms $z_{0}$ and $h / L$ indicate that the profile of the vertical concentration is affected by these two factors. The qualitative features of the vertical spread can be investigated using the general equation (23) for $\hat{Z}_{\sigma}$.

(i) Mixing layer

In this layer, $K_{z}$ was assumed to be constant in the upper convective layer, so that $K_{\max }$ is given by

$$
K_{\max }=\alpha C_{1}{ }^{\prime} w_{*} h
$$

Substituting equation (24) into (18), we have

$$
R e=\frac{U_{h}}{C_{1}^{\prime} w_{*}}
$$

From equation (23) and (25), $\hat{Z}_{\sigma}$ can be written in the form

$$
\hat{Z}_{\sigma}=f\left(\frac{\alpha w_{*}}{U_{h}} \cdot \frac{x}{h}, \frac{z_{0}}{h}\right)
$$

Thus, for the mixing layer, $w_{*} / U_{h^{\bullet}} x / h$ appears 


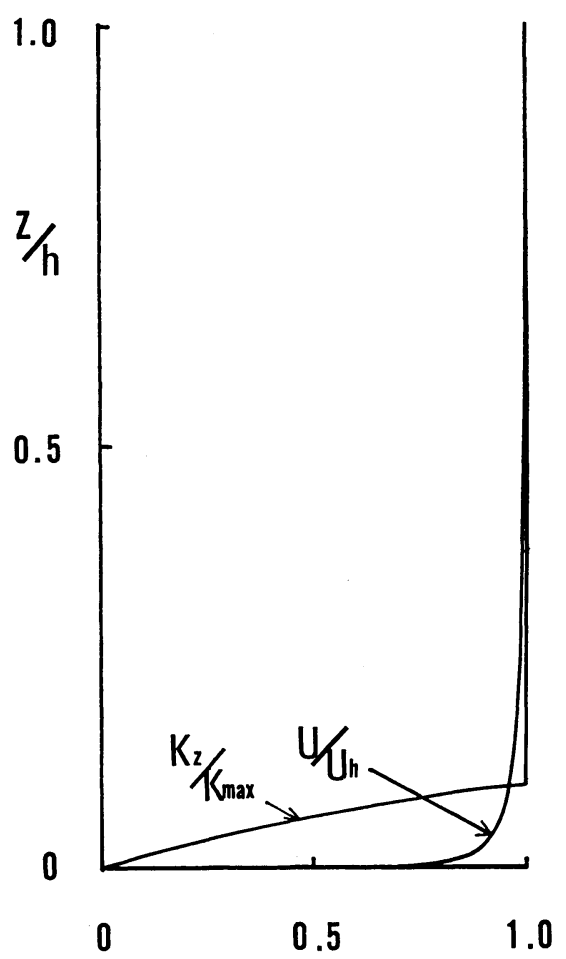

a) mixing layer

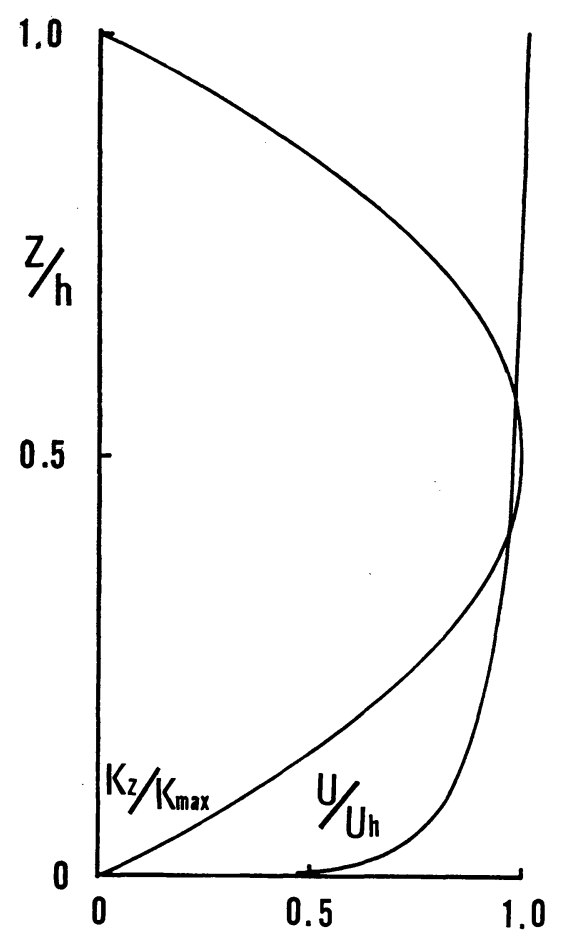

b) neutral layer

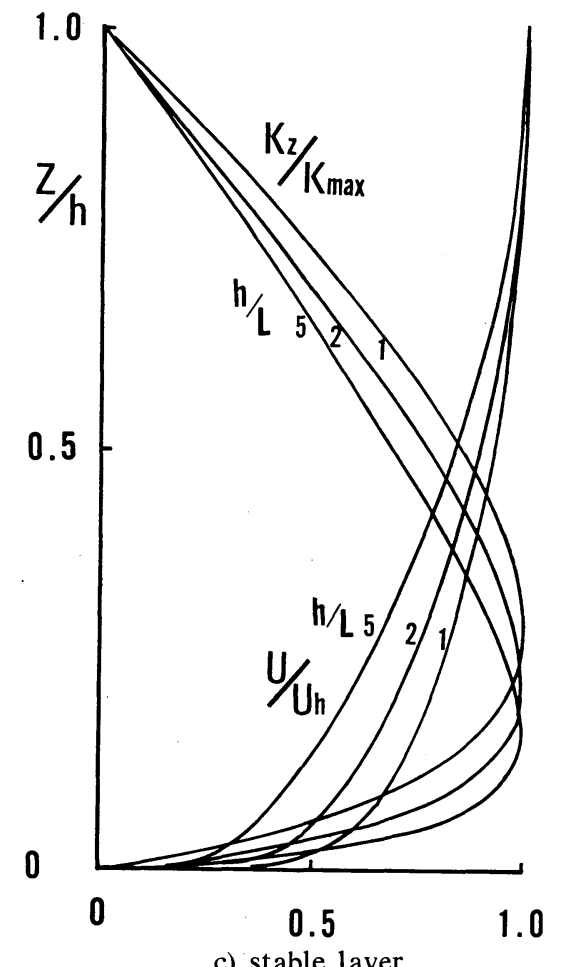

c) stable layer

Fig. 1 Profiles of normalized wind speed for $\hat{z}_{0}=10^{-4}$ and eddy diffusivity. a) mixing layer, b) neutral layer, c) stable layer.

to be one of the characteristic factors for the development of $\hat{Z}_{\sigma}$. The other factor, $z_{o} / h$, represents the contribution of the surface roughness on the profile of vertical concentration.

Deardorff and Willis (1975) have shown that the appropriate dimensionless time for diffusion in the mixing layer is given by

$$
\hat{t}=\frac{w_{*}}{h} \cdot t=\frac{w_{*}}{h} \cdot \frac{x}{\bar{U}}
$$

where $\bar{U}$ is the uniform mean wind speed in the mixing layer. In the limit $z_{0} \rightarrow 0, \bar{U}$ tends to $U_{h}$, so that our $\hat{x}$ becomes equivalent to $\hat{t}$ in (27). Since $w_{*}$ and $\bar{U}$ are given independently, the essential parameter for the development of the smoke spread is not the downwind distance itself but the traveling time of the smoke.

(ii) Neutral layer

The eddy diffusivity in this layer takes a maximum value at $z=1 / 2$ and $K_{\max }$ becomes

$$
K_{\max }=\frac{\alpha}{4} k u_{* 0} h
$$

Substituting equation (28) into (18) and putting 
$z=h$ in eqaution (14), we have

$$
\begin{aligned}
R e & =\frac{4}{k} \cdot \frac{U_{h}}{u_{* 0}}=-\frac{4}{k^{2}}\left(\ln \frac{h}{z_{0}}+\frac{z_{0}}{h}-1\right) \\
& \doteqdot \frac{4}{k^{2}}\left(\ln \frac{h}{z_{0}}-1\right)
\end{aligned}
$$

Thus, from equations (23) and (29), we obtain

$$
\begin{aligned}
\hat{Z}_{\sigma} & =\frac{Z_{\sigma}}{h}=f_{2}\left(\frac{u_{* 0}}{U_{h}} \cdot \frac{\alpha x}{h}, \frac{z_{0}}{h}\right) \\
& =f_{2}\left(\frac{x}{h} \cdot \frac{\alpha k^{2}}{\ln \left(\frac{h}{z_{0}}\right)-1}, \frac{z_{0}}{h}\right)
\end{aligned}
$$

As shown in equation (30), $u_{*_{o}} / U_{h}$ is only a function of $\hat{z}_{0}$. Therefore, $\hat{Z}_{\sigma}$ should be given as a function of the downwind distance once $\hat{z}_{0}$ is fixed. In the mixing layer, however, $\hat{Z}_{\sigma}$ depends on the traveling time $\hat{t}$ as mentioned above.

(iii) Stable layer

In the stable layer, the height at which $\hat{K}_{z}$ is at its peak value is

$$
\hat{z}_{\max }=\frac{z_{\max }}{h}=\frac{L}{\beta h}\left(\sqrt{1+\beta \frac{h}{L}}-1\right)
$$

Apparently $\hat{z}_{\max }$ decreases with increasing $h / L$ (see Figure 1-c). Substituting eqaution (31) into (15) we have

$$
K_{\max }=\alpha k u_{* 0} h\left(\frac{L}{\beta h}\right)^{2}\left(\sqrt{1+\beta \frac{h}{L}}-1\right)^{2}
$$

Thus, from equation (16), (18) and (32) we obtain

$$
R_{e}=\frac{1}{k^{2}}\left(\ln \frac{h}{z_{0}}-1+\frac{\beta h}{2 L}\right)\left(\sqrt{1+\beta \frac{h}{L}}+1\right)^{2}
$$

where we neglected $\hat{z}_{0}$ compared to 1 . Since $\boldsymbol{R}_{\boldsymbol{e}}$ in the stable layer does not include the wind speed explicitly as in the neutral layer, $Z_{\sigma}$ should only depend on the downwind distance.

\section{Calculations}

Numerical calculations were carried out using the Gauss-Seidel method with a central difference approximation in the vertical direction and a upwind difference in the mean wind direction. The grid length $\Delta_{\hat{z}}(=\Delta z / h)$ in the vertical direction was taken to be 0.005 and the grid length in the mean wind direction was chosen so that the ratio $\Delta z / \Delta x$ satisfies the computational stability condition. Near the source, a smaller grid was used to minimize the discretization error. The calculated concentration was evaluated by the characteristic spread $Z_{\sigma}$, which is defined by the distance between the height of the maximum concentration and the height at which the concentration decreases to $60 \%$ of maximum.

The parameter

$$
\bar{z}=\int_{0}^{\infty} C z d z / \int_{0}^{\infty} C d z
$$

or

$$
\sigma_{z}=\int_{0}^{\infty} C z^{2} d z / \int_{0}^{\infty} C d z
$$

is often used to characterize the development of vertical spread; $\bar{z}$ is meaningful for diffusion from the surface, but it cannot be a measure of spread from elevated sources. Another parameter, $\sigma_{z}$, is useful for either elevated or ground level sources. But if the vertical distribution of the smoke is not axisymmetric, we have to introduce one more parameter to characterize the nonsymmetry. We are presently investigating the diffusion from elevated sources and making comparisons with that from surface sources (Mizuno et al., 1980). For the vertical diffusion from elevated sources, nonsymmetry of the concentration is expected, so that abovedefined $Z_{\sigma}$ is considered suitable to represent and compare the vertical spread of diffusion from various sources heights. $Z_{\sigma}$ is approximately equivalent to the standard deviation of the concentration, $\sigma_{z}$, if the distribution function is Gaussian. The profile of the vertical distribution of concentration is often approximated in the following form

$$
\begin{aligned}
C & =C_{0} \exp \left(-A\left[\frac{z}{\sigma_{z s}}\right]^{s}\right) \\
& =\frac{Q \sigma_{z s} s \Gamma(1 / s)^{3 / 2}}{2 U \Gamma(3 / s)^{1 / 2}} \exp \left(-A\left[\frac{z}{\sigma_{z s}}\right]^{s}\right)
\end{aligned}
$$

where

$$
A=\left(\frac{\Gamma(3 / s)}{\Gamma(1 / s)}\right)^{s / 2}
$$

and $s$ is a nondimensional constant (shape factor), $\sigma_{z S}$ is the standard deviation of the smoke spread and $C_{o}$ is the concentration at the ground surface. From equation (34) we can derive that $Z_{\sigma}$ is related to $\sigma_{z s}$ by

$$
\frac{\sigma_{z s}}{Z_{\sigma}}=A^{1 / s}(-\ln 0.6)^{-1 / s}
$$

As shown in (36), the relation between $\sigma_{z s}$ and $Z_{\sigma}$ depends on the shape factor $s$.

(i) Mixing layer 
Calculations carried out for four cases of $\hat{z}_{0}$ are shown in Fig. 2, where the relation of $\hat{Z}_{\sigma}$ and $\hat{C}_{0}$ versus $\hat{x}$ are shown. First, we compare the results with the O'Neill data (Barad, 1958). Nieuwstadt (1979) rearranged the data of the O'Neill diffusion experiments and plotted the variation of $C_{o} \bar{U} h / Q$ against $w_{*} x / \bar{U} h$, where $C_{o}$ was estimated from the integrated concentration to the lateral direction to the wind direction measured at $z=50 \mathrm{~cm}$ (Fig. 3). Chaudhry and Meroney (1973) and Horst (1979) applied Lagrangian similarity models to the diffusion from a ground level source using the dimensionless diffusivity of heat $\phi_{h}=k u_{*_{0}} z / K_{h}$ and showed that their calculations agreed well with the O'Neill data. $K_{h} / K_{m}$ in an extremely unstable layer is not known precisely yet but estimated to be about 2 to 3 (see Monin and Yaglom, 1971). In our tudy, we assume that $\sigma=K_{z} / K_{m} \simeq K_{h} / K_{m} \simeq 2$, in the mixing layer.

For most of the unstable layers of the O'Neill experiments, $\hat{z}_{0}$ is of the order of $10^{-5}$. The solid lines in Fig. 3 are the calculations with $\alpha=2$. The dashed line is the laboratory data of Deardorff and Willis (1975). The calculated concentrations agree well with the field experiment, except for large $w_{*} x / \bar{U} h$ where the experimental data decrease more rapidly than the calculations. One of the reasons for this discrepancy is that

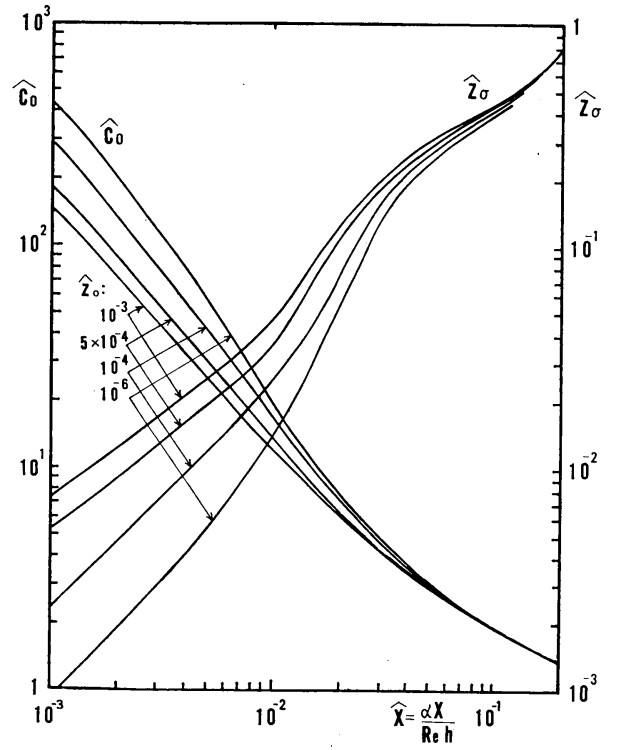

Fig. 2 Dimensionless vertical spread and normalized concentration at a ground surface as a function of dimensionless downwind distance and $\hat{z}_{0}$ (mixing layer).

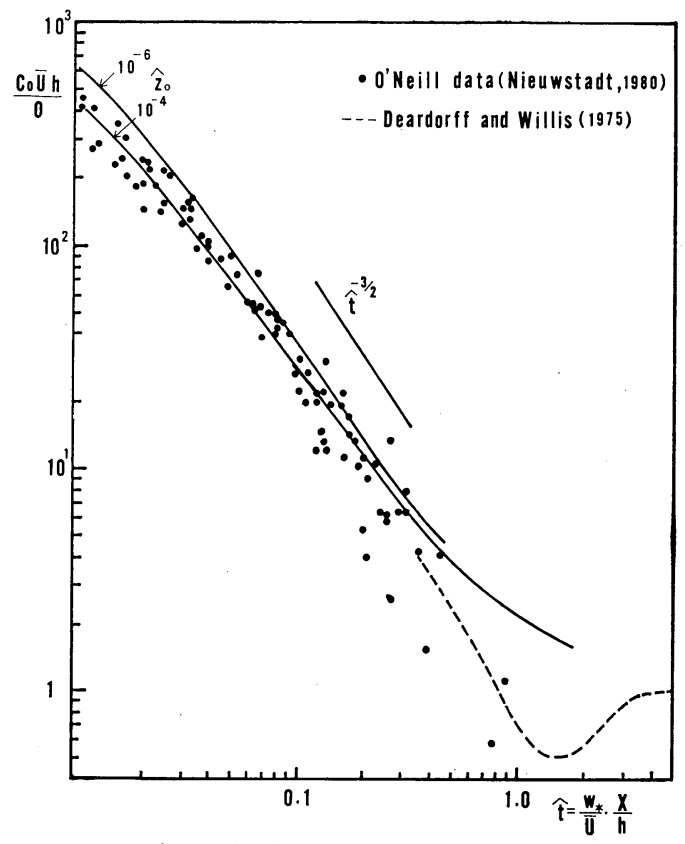

Fig. 3 Dimensionless cross-wind integrated concentration at a ground surface as a function of $\hat{t}$ in the mixing layer. Solid lines are the calculations with $\alpha=2.0$.

the error in estimating $C_{o}$ becomes larger with increasing downwind distance, since the observed concentrations become very low. Also, as indicated by Deardorff and Willis (loc. cit.), the effect of the elevated maximum concentration might appear after long traveling time. This effect is not accounted for in our model.

$\bar{z}$ at the downwind distance $x=100 \mathrm{~m}$ was estimated using the vertical concentration distribution (Nieuwstadt and Ulden, 1978). The comparison of $\bar{z}$ is shown in Fig. 4. the experimental results are somewhat smaller than the calculations. As shown in Monin and Yaglom (1971), in the limit of the free convective condition in the surface layer, $\bar{z}$ should be related to the traveling time, $t$, of the smoke plume by

$$
\bar{z}=a \cdot\left(\frac{w_{*} t}{h}\right)^{3 / 2} \cdot h
$$

The broken line in Fig. 4 represents (37) with the universal constant $a=1.3$.

Assuming a Gaussian distribution of material in the vertical direction, the standard deviation of spread is often estimated using measured concentration at the ground surface:

$$
\sigma_{z 2}=\sqrt{\frac{2}{\pi}} \frac{Q}{C_{0} U_{e}}
$$




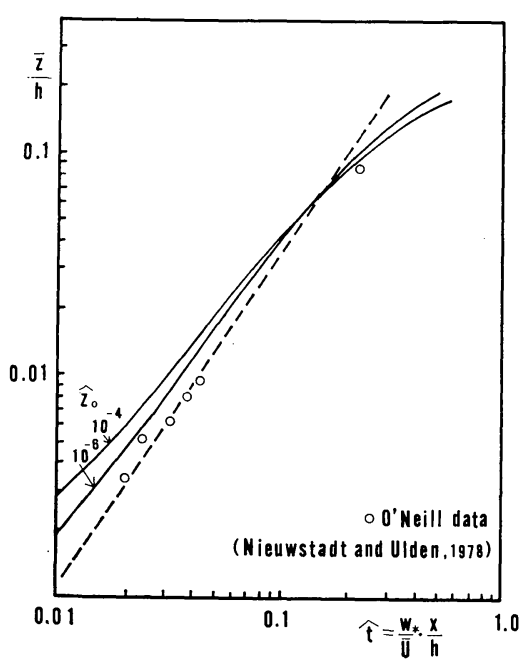

Fig. 4 Dimensionless mean height of diffusing material, $\bar{z} / h$, as a function of $\hat{t}$. Solid lin $\approx$ s are the calculations with $\alpha=2.0$. Dashed line corresponds to $1.3 \cdot \hat{t}^{2 / 3}$.

where suffix 2 indicates the shape factor $s=2$ and $U_{e}$ is the effective transport wind speed. If the real profile of the concentration is not Gaussian, $\sigma_{z 2}$ is not equal the standard deviation $\sigma_{z s}$ of the smoke. The relation between $\sigma_{z 2}$ and $\sigma_{z S}$ is given from (34) by

$$
\frac{\sigma_{z 2}}{\sigma_{z s}}=\sqrt{\frac{2}{\pi}} \frac{1}{s}\left(\frac{\Gamma(1 / s)^{3}}{\Gamma(3 / s)}\right)^{1 / 2}
$$

Thus from (36) and (39) we have

$$
\frac{\sigma_{z 2}}{Z_{\sigma}}=\frac{2}{\sqrt{\pi}} \frac{\Gamma(1 / s)}{s}
$$

The value $\sigma_{z 2} / Z_{\sigma}$ is 1.12 when $s=1$ and 1.01 when $s=3$, so that if $1 \leq s \leq 3, Z_{\sigma}$ can be approximately regarded as $\sigma_{z 2}$ estimated from relation (38).

The St. Louis experiment (McElroy and Pooler, 1968) gives $\sigma_{z 2}$ as a function of the traveling time of the diffusing matter. In the experiment, $z_{0}$ was approximately $3 \mathrm{~m}$. Neither the height of the mixing layer nor the heat flux near the surface were obtained. We assume, as possible values, $w_{*} \cong 2 \mathrm{~m} / \mathrm{s}$ to $2.5 \mathrm{~m} / \mathrm{s}$ for the unstable case and $h=2,000 \mathrm{~m}$. Fig. 5 shows the comparison of the experiments and the calculations. In the figure, the runs which contain $\sigma_{z 2}>2,000 \mathrm{~m}$ were excluded. The calculated $Z_{\sigma}$ agree fairly well with the experiments, considering the uncertainty of the convection and the scatter of the data.

Finally we compare the calculations with the Pasquill-Gifford chart, which was drawn on the

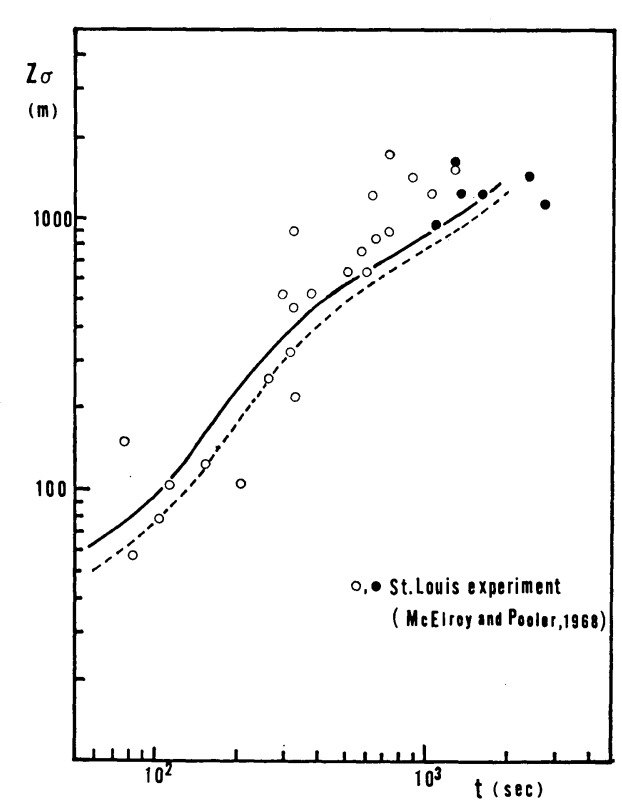

Fig. 5 Comparison of calculated $Z \sigma$ with experimental vertical spread $\sigma_{z 2}$ (all the data belong to modified gustness factor classes $B_{1}{ }^{\prime}$ and $B_{2}{ }^{\prime}$ defined by McElroy and Pooler, 1968). Blocked-circles are the data considered to be significantly affected by a lid. Solid line $w_{t}=2 \mathrm{~m} / \mathrm{s}$, dashed line $w_{t}=2.5$ $\mathrm{m} / \mathrm{s}$.

bases of diffusion experiments in the atmosphere. This chart is widely utilized for atmospheric environment problems and familiar to environmentalists. The characteristics of the present study can be clarified by comparison with the chart. According to equation (26), $Z_{\sigma}$ may be obtained when $h, w_{*} / U_{h}$ and $z_{0} / h$ are fixed. Since $\mathrm{h}$ and $w_{*}$ are given once the heat flux $q_{0}$ is fixed, then $q_{0}$, $U_{h}$ and $z_{o}$ become independent parameters. As for Pasquill's stability categories, surface wind speed and insolation are independent parameters. Thus we need to change $U_{h}$ and $q_{o}$ to $U_{10}$ (wind speed at $10 \mathrm{~m}$ height) and $I$ (isolation near the surface). $U_{h}$ is related to $U_{10}$ through equation (12). The relation between the heat flux and the insolation has not been given theoretically yet. Empirically, Gamo et al. (1976) found that $q_{o}$ is approximately $40 \%$ of the insolation. Therefore, we assume $q_{o}=0.4 \mathrm{I}$. Table 1 shows typical values of the stability parameters and corresponding $R e$ numbers.

The vertical spread of the Pasquill-Gifford chart was originally given by the height $(H)$ at which the concentration falls to $10 \%$ of the 
maximum ground level concentration. The relation between $H$ and $Z_{\sigma}$ can be given using equations (34) and (36).

$$
\frac{H}{Z_{\sigma}}=\left(\frac{\ln 0.1}{\ln 0.6}\right)^{1 / s}=4.6^{1 / s}
$$

The Pasquill-Gifford chart is represented by $\sigma_{z, p} \cong H / 2.14$ instead of $H . \sigma_{z, p}$ equals the standard ard deviation of the vertical spread, if the distribution is Gaussian. From (41) we have

$$
\frac{\sigma_{z, p}}{Z_{\sigma}}=\frac{4.61^{1 / s}}{2.14}
$$

In order to compare our results with the PasquillGifford chart, it is necessary to convert $Z_{\sigma}$ to $\sigma_{z, p}$ through (42).

Fig. 6 shows the variation of $Z_{\sigma}$, where as typical values, we put $h=1,000 \mathrm{~m}$ and $q_{o}=70$ $\mathrm{cal} / \mathrm{m}^{2} \mathrm{~s}$, referring to Table 1 . Since the shape factor $s$ is estimated to be nearly 1 for short diffusion time (see Table 3), from (42) we can infer that $2 Z_{\sigma}$ should corresponding to $\sigma_{z, p}$. In the very unstable layer, Nieuwstadt and Ulden (1978) have shown that $s$ is nearly 1 , which is the same result as our calculation. In Fig. 6, if $z_{o}$ is in the range of $1 \mathrm{~cm}$ to $10 \mathrm{~cm}$, our results roughly correspond to classes $\mathrm{A}$ to $\mathrm{C}$ at short distance except for $U_{10}=1 \mathrm{~m} / \mathrm{s}$. With the increase of wind speed, $2 Z_{\sigma}$ may become smaller than class $C$. If the wind speed increases in the thermally convective layer, forced convection should be induced near the ground surface. Probably this effect causes vertical diffusion to develop and $Z_{\sigma}$ at short distances may approach the spread of the neutral condition. In our model, such a transition layer was not taken into account.

\section{(ii) Neutral layer}

In the neutral layer, $\hat{Z}_{\sigma}$ can be calculated once the parameter $\hat{z}_{0}$ is given. Fig. 7 shows $\hat{Z}_{\sigma}$ and

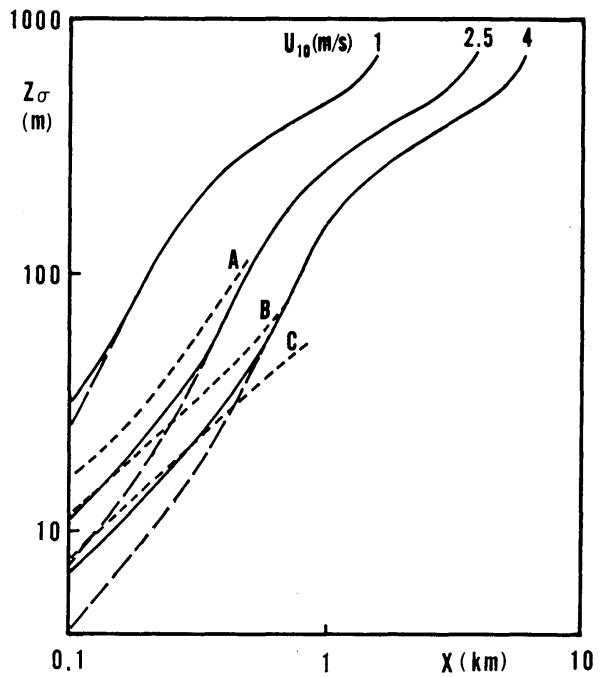

Fig. 6 Variation of vertical spread with wind speed $U_{10}$ for $z_{0}=10 \mathrm{~cm}$ ( $(-)$ and $z_{0}=1 \mathrm{~cm} \mathrm{(-} \mathrm{-} \mathrm{-} \mathrm{);} h=1,000 \mathrm{~m}$ and $q_{0}=70 \mathrm{cal} / \mathrm{m}^{2} \mathrm{~s}$. (- - -) represents Pasquill-Gifford chart.

$\hat{C}_{0}$ plotted against $\hat{x}$ for three cases of $\hat{z}_{0}$. The relation between $\hat{Z}_{\sigma}$ and $\hat{x}$ is converted into the real scales of $Z_{\sigma}$ and $x$, when $R e$ and $\alpha$ are fixed. $R e$ numbers in the neutral and stable layers depend on $\hat{z}_{0}$ and $h / L$, as shown in equation (33), where the neutral layer is a special case of $h / L=0$. Fig. 8 shows the variation of $R e$.

According to the Lagrangian similarity model (Chaudhry and Meroney, 1972; Horst, 1979), calculations with the nondimensional eddy diffusivity of heat proposed by Businger et al. (1971) fiit the O'Neill experiments in the near-neutral and slightly stable layers, as well as in the unstable layer. Businger et al. (1971) found that in neutral and stable layers, $K_{h} / K_{m}=1.35$, so that at first we assumed $\alpha=K_{z} / K_{m} \cong K_{h} / K_{m}=1.35$.

\begin{tabular}{|c|c|c|c|c|c|c|c|c|c|c|c|}
\hline \multicolumn{2}{|c|}{$\begin{array}{l}\text { Insolation } \\
\text { (representative Ins.) } \\
\text { equivalent heatflux } q_{0} \\
\text { height of boundary layer }\end{array}$} & $\begin{array}{l}(\mathrm{ly} / \mathrm{hr}) \\
(\mathrm{ly} / \mathrm{hr}) \\
\left(\mathrm{cal} / \mathrm{m}^{2} \mathrm{~s}\right) \\
(\mathrm{m})\end{array}$ & & $\begin{array}{r}>50 \\
62.5 \\
70 \\
1000\end{array}$ & 500 & \multicolumn{3}{|c|}{$\begin{array}{c}50 \sim 25 \\
37.5 \\
42\end{array}$} & \multicolumn{3}{|c|}{$\begin{array}{c}<25 \\
12.5 \\
14\end{array}$} \\
\hline $\begin{array}{l}\text { wind velocity at } \\
z=10 \mathrm{~m}(\mathrm{~m} / \mathrm{s})\end{array}$ & $\begin{array}{l}\text { (repr } \\
\text { velo }\end{array}$ & $\begin{array}{l}\text { ntative wind } \\
\mathrm{y} \mathrm{m} / \mathrm{s})\end{array}$ & & & & & & & & & \\
\hline$\sim 2$ & & 1 & A & 17 & 21 & $A-B$ & 21 & 25 & B & 30 & 36 \\
\hline $2 \sim 3$ & & 2.5 & $A-B$ & 43 & 52 & B & 51 & 61 & C & 74 & 89 \\
\hline $3 \sim 5$ & & 4 & B & 60 & 72 & C & 72 & 86 & $\mathrm{C}$ & 104 & 125 \\
\hline $5 \sim 6$ & & 5.5 & C & 86 & 103 & & & & & & \\
\hline
\end{tabular}

Table $1 R e$ numbers in the mixing layer 


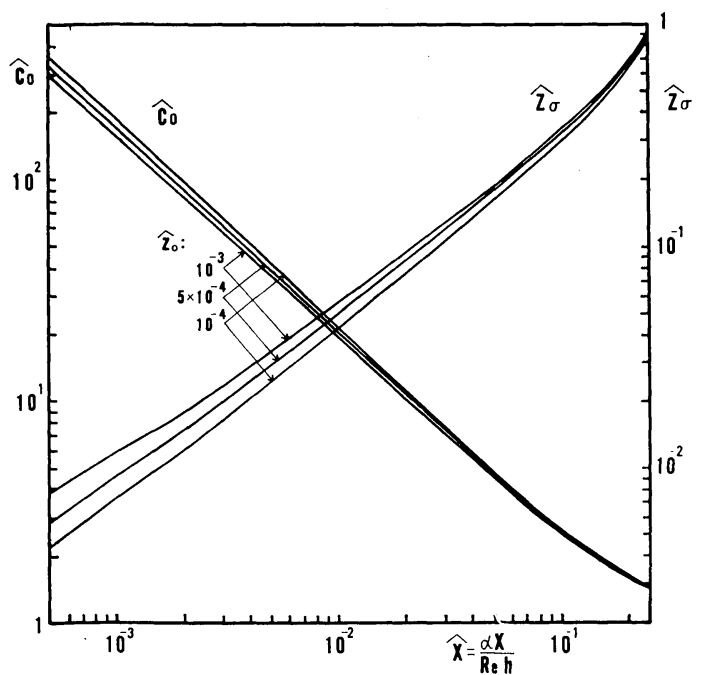

Fig. 7 Dimensionless vertical spread and normalized concentration at a ground surface as a function of dimensionless downwind distance (neutral layer).

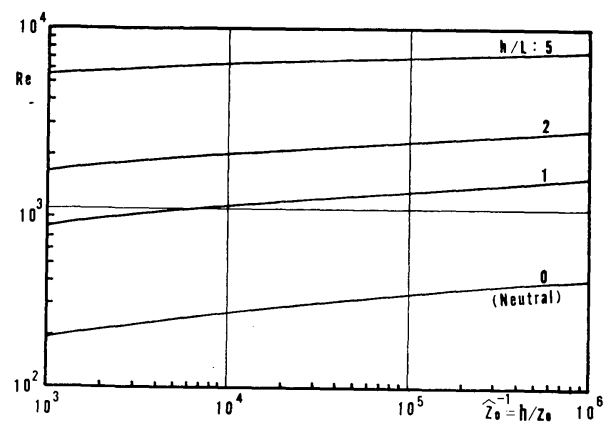

Fig. 8 Variation of $R e$ number as a function of $z_{0}^{-1}$ and $h / L$. (neutral and stable layers).

However, in comparison with the experimental data, it was found that somewhat larger value is preferable. Thus, we assume $\alpha=1.55$ in nearneutral to stable layers.

Relations between $Z_{\sigma}$ and $x$ are shown in Fig. 9 for some typical cases of $z_{o}$ and $h$. We may see that at short downwind distance, $Z_{\sigma}$ depends almost entirely on $z_{o}$ and the effect of the boundary layer thickness $h$ can be neglected. When $Z_{\sigma} \geq h / 2$ the reflection of the plume by the upper boundary begins to affect the development of $Z_{\sigma}$.

The comparison with the St. Louis experiments is shown in Fig. 10, where $\sigma_{z 2}$ (experiment) and $Z_{\sigma}$ (calculation) are shown. In the experiments, only near-neutral cases are chosen. In order to compare the $\sigma_{z 2}$ of the experiments, the calcu- lated $Z_{\sigma}$ should be converted to $\sigma_{z 2}$ through equation (40). Since the shape factor $s$ in the neutral layer is $1 \leq s \leq 2$, from equation (40) we may expect $Z_{\sigma} \cong \sigma_{z 2}$. Taking into account the error of the data, the calculations agree well with the experiments.

In Fig. 9, the Pasquill-Gifford class $D$ is also shown. In order to compare our results with the chart, we have to change $Z_{\sigma}$ to $\sigma_{z, p}$ through equation (42) as discussed before. In the neutral layer, the shape factor $s$ is nearly 1 at short distance and gradually increases with distance (see Table 3), so that we may expect that near the source $\sigma_{z, p} \cong 2 Z_{\sigma}$ and $\sigma_{z, p} \cong 1.3 Z_{\sigma}$ at long distances. The calculated $\sigma_{z, p}$ is not shown here, but qualitatively our results with $z_{o} 1 \mathrm{~cm}$ to 10 $\mathrm{cm}$ correspond to the Pasquill-Gifford chart. One should note that the vertical profile of the concentration is not given by a simple Gaussian distribution function in the neutral layer.

The comparison with the O'Neill data will be discussed in the section on the stable layer. (iii) Stable layer

In the stable layer, $\hat{Z}_{\sigma}$ may be calculated given $h / L$ and $z_{0}$. According to Yamamoto et al.'s observation (1979), $h / L$ takes a value of about 1 to 5 in the stable layer. As a representative value, therefore, we put $h / L=1$ for a slightly stable layer, $h / L=2$ for a moderately stable layer and

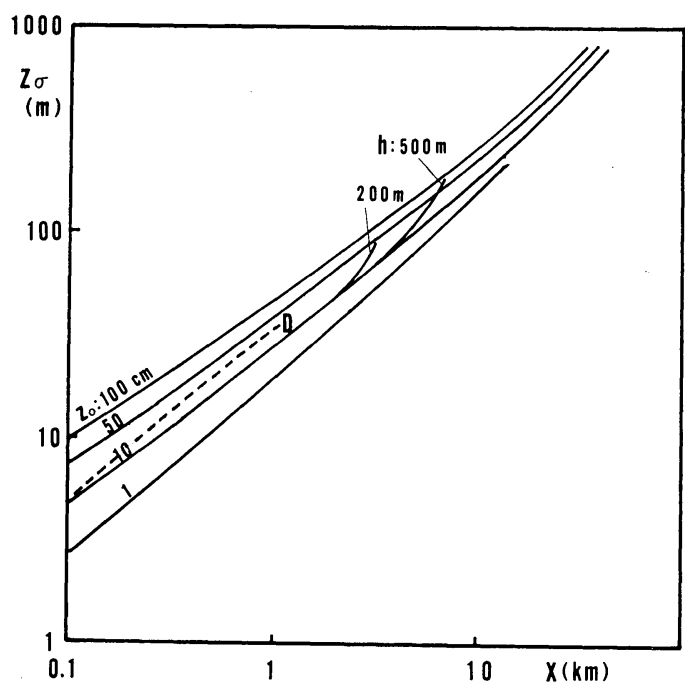

Fig. 9 Variation of vertical spread as a function of roughness length of a ground surface and the height of neutral houndary layer. Solid lines without ' $h$ ' are the calculations for $h=1,000 \mathrm{~m}$. Dashed line corresponds to Pasquill-Gifford class D. 


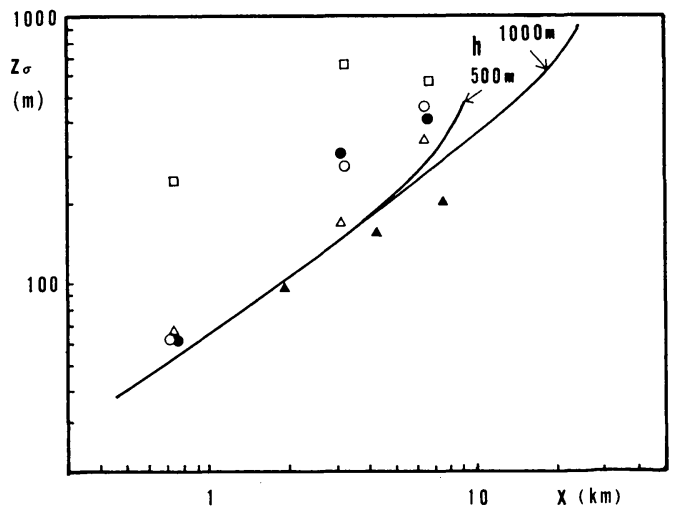

Fig. 10 Comparison of calculated $Z \sigma$ with experimental vertical spread $\sigma_{z 2}$. Points are from St. Louis study by McElroy and Pooler (1968), near-neutral cases. No. 16(○), 24( $\square)$, $37(\triangle), 42(\Delta), 43(\odot)$.

$h / L=5$ for a strongly stable layer.

Fig. 11 shows the resulting relations of $\hat{Z}_{v}$ and $\hat{C}_{0}$ versus $\hat{x}$. Using $R_{e}$ numbers shown in Fig. 8 and $\alpha(=1.55)$, we get the relations of the real scale of $Z_{\sigma}$ and $x$. The case where $h / L$ changes but $\mathrm{h}$ and $z_{0}$ are fixed is shown in Fig. 12. This situation corresponds to a hypothetical stable layer in which $h / L$ increases but $\mathrm{h}$ remains constant. As is apparent from Fig. 12, the slope of $Z_{\sigma}$ decreases with increasing $h / L$. The case where $h / L$ and $z_{0}$ are fixed but $h$ changes is shown in Fig. 13. We can see that $Z_{\sigma}$ is suppressed when $h$ decreases, whereas in the neutral layer $Z_{\sigma}$ hardly depends on $h$ except in the region where $Z_{\sigma}$ becomes larger than $h / 2$. This is because $K_{\max }$ decreases when $h / L$ increases and the height of $K_{\max }$ becomes much lower than that found in the neutral layer, then the diffusion in the upper part of the layer should be much suppressed.

Now, we consider the case where only $z_{o}$ varies with $h$ and $h / L$ constant. The increase of $Z_{\sigma}$ with $z_{o}$ is as large as in the neutral layer (Fig. 14). In comparison with Figs. 13 and 14, it appears that near the source, for instance $x<0.1$ $\mathrm{km}, Z_{\sigma}$ depends mostly on the roughness length $z_{o}$, is not dependent on $h$ nor $h / L$.

Here we again use the O'Neil data to compare with the calculations. Since $C_{o} U_{10} / Q$ can be obtained with little error from the data, we compare our results using the concentration $C_{0} U_{10} / Q$ instead of $Z_{\sigma}$.

The height of the inversion layer was inferred from the intersection of the temperature profiles observed by the tower measurement below $16 \mathrm{~m}$

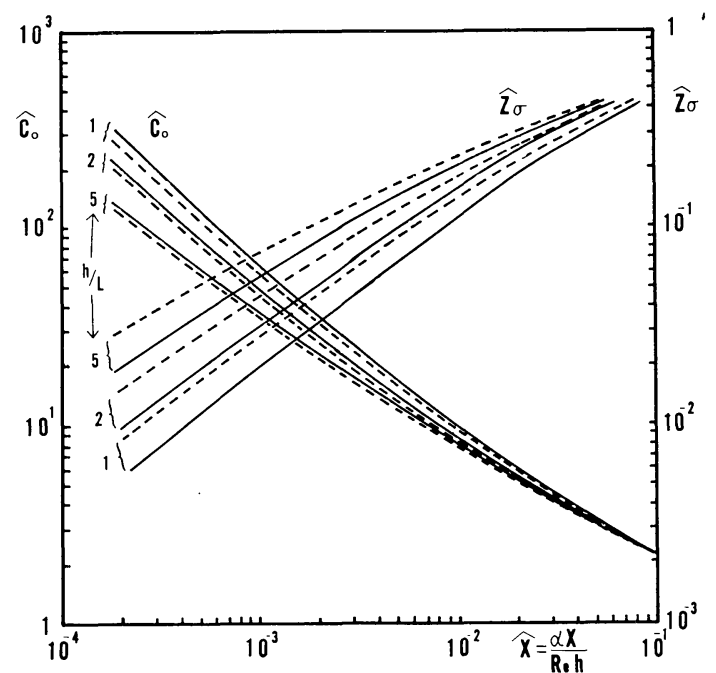

Fig. 11 Dimensionless vertical spread and normalized concentration at a ground surface as a function of dimensionless downwind distance (stable layer). Solid line: $\hat{z}_{3}=10^{-4}$, dashed line: $\hat{z}_{0}=10^{-3}$.

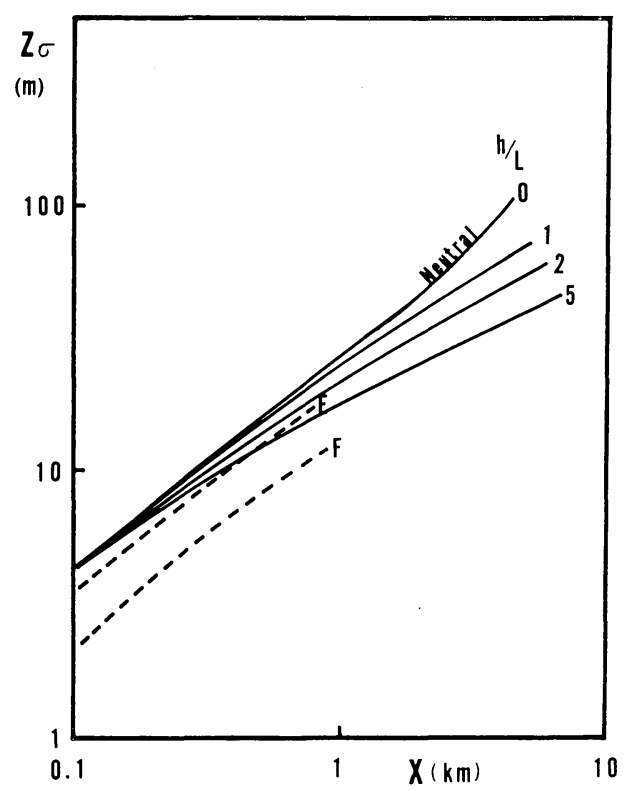

Fig. 12 Variation of vertical spread with $h / L$ for $h=200 \mathrm{~m}$ and $z_{0}=10 \mathrm{~cm}$. Dashed lines represent Pasquill-Gifford classes $\mathrm{E}$ and $\mathrm{F}$.

and by airborne measurement in the upper layer. Two examples of the potential temperature profiles and estimated $h$ are shown in Fig. 15. The data of the O'Neill experiments are listed in Table 2. As for Monin-Obukhov length $L$, we used the values estimated by Nieuwstadt and 


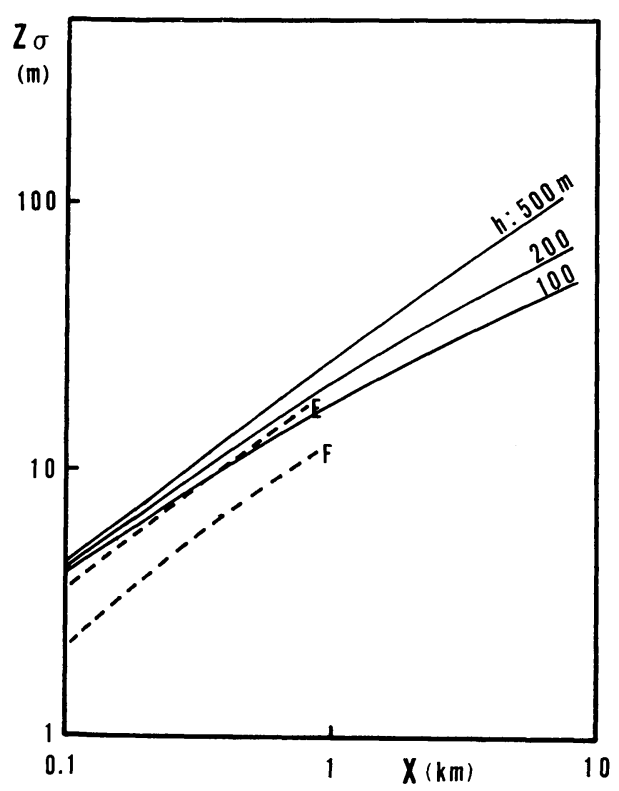

Fig. 13 Variation of vertical spread with the height of stable layer for $h / L=2$ and $z_{0}=10 \mathrm{~cm}$.

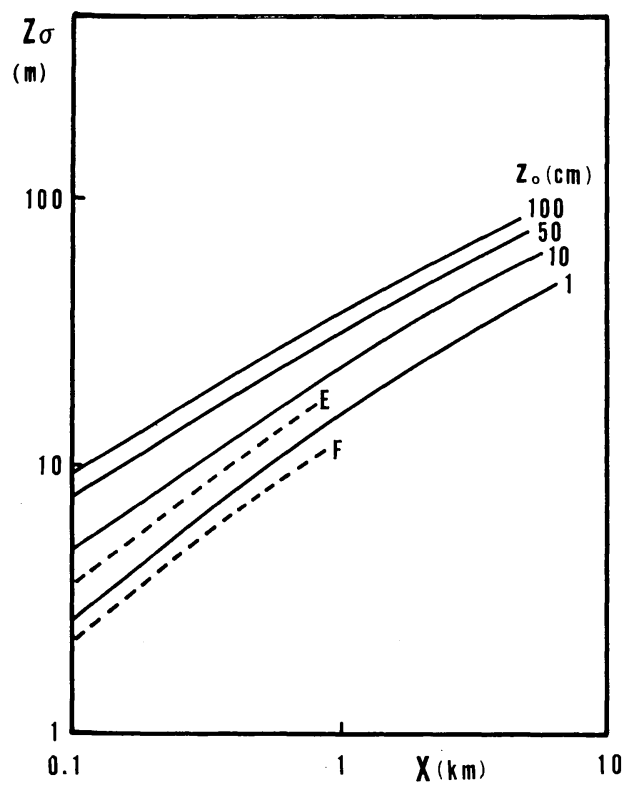

Fig. 14 Variation of vertical spread with the roughness length of a ground for $h=200 \mathrm{~m}$ and $h / L=2$.

Ulden (1978). The data are classified into two cases, case $1(h \geq 200 \mathrm{~m})$ and case $2(h<200 \mathrm{~m})$, in order to compare with the calculations.

The solid lines in Fig. 16 are the calculated relations between $C_{o} U_{10} / Q$ and $x$ with $z_{o}=0.6$
Table 2 O'Neill data, nearly-neutral to stable cases

\begin{tabular}{c|c|c|c|c}
\hline & RUN & $\begin{array}{c}h \\
(\mathrm{~m})\end{array}$ & $\begin{array}{c}L^{-1} \\
\left(\mathrm{~m}^{-1}\right)\end{array}$ & $h / L$ \\
\hline & 21 & 250 & 0.006 & 1.5 \\
case 1 & 22 & 280 & 0.005 & 1.4 \\
$(h \geq 200 \mathrm{~m})$ & 24 & 330 & 0.004 & 1.3 \\
& 46 & $(200)$ & 0.039 & 1.8 \\
& 57 & - & -0.005 & - \\
\hline & 14 & $(25)$ & 0.600 & 15 \\
case 2 & 32 & $(20)$ & 0.120 & 2.4 \\
$(h<200 \mathrm{~m})$ & 36 & 110 & 0.127 & 14 \\
& 37 & 60 & 0.010 & 0.6 \\
& 59 & $(60)$ & 0.095 & 5.7 \\
\hline
\end{tabular}

$h$ in parentheses are not reliable. $L$ are the values estimated by Nieuwstadt and Ulden (1978).

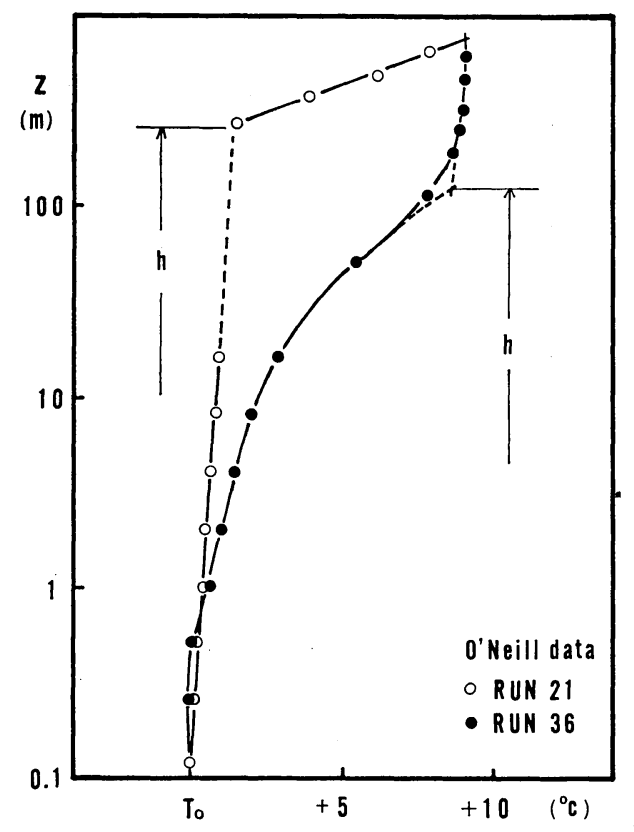

Fig. 15 Potential temperature profile and estimated height of the surface inversion layer.

$\mathrm{cm}$ and $h=300 \mathrm{~m}$. This situation roughly corresponds to case 1 . The calculations with $z_{0}=0.6$ $\mathrm{cm}$ and $h<200 \mathrm{~m}$ are shown in Fig. 17, which are to compare with case 2 . Experimental results with $h / L \leq 2$, and $-1 / L<0.01$ (nearly neutral layer) fall in a rather narrow range, almost independent of $h$, and a good agreement with the calculations is seen. For the strongly stable layer, where $h / L \geq 5$, calculated concentration with $h \leq 60 \mathrm{~m}$ becomes much larger than that with 


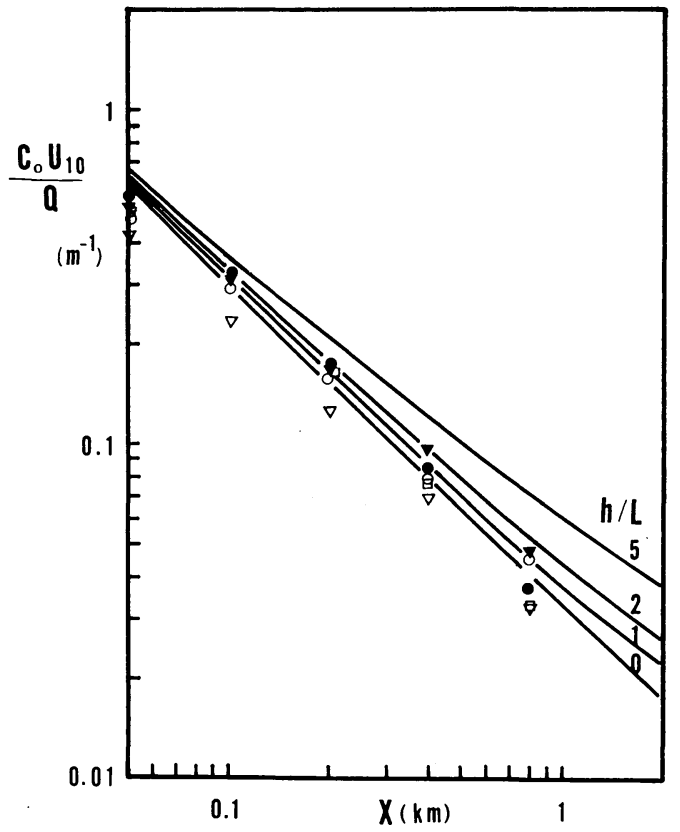

Fig. 16 Comparison of calculated concentration at a ground surface with experimental cross-wind integrated concentration at $z=50 \mathrm{~cm}$ (O'Neill data). Solid lines are calculated concentration for $h=300 \mathrm{~m}$ and $z_{0}=0.6 \mathrm{~cm}$. No. $21(\bigcirc)$, 22(○), 24( $\nabla), 46(\nabla), 57(\square)$. Refer to case 1 in Table 3 .

$h=300 \mathrm{~m}$. The calculations in such a strongly stable layer also agree well with the experiments.

Compared to the Pasquill-Gifford chart, our results fall into the class $\mathrm{E}$ when $z_{0}$ is in the range of $1 \mathrm{~cm}$ to $10 \mathrm{~cm}$ with $200 \mathrm{~m} \leq h \leq 500 \mathrm{~m}$ and $h / L \fallingdotseq 1$. Here, we used the relation $Z_{\sigma} \cong \sigma_{z, p}$ because the shape factor $s \cong 2$ in the stable layer (Table 3). When $h$ decreases or $h / L$ increases beyond the above vlues, the calculated vertical spreads are much more suppressed.

\section{Vertical concentration distribution}

In the previous sections we have discussed the characteristics of the vertical spread $Z_{\sigma}$. The vertical concentration distribution is, however, not characterized by $Z_{\sigma}$ alone. Fig. $18 \mathrm{a}, \mathrm{b}$ and $\mathrm{c}$ show typical dimensionless concentration distributions in mixing, neutral and stable layers, respectively. The dashed lines in the figures correspond to the Gaussian distribution function which coincides with the calculated concentration at the ground $\left(\hat{C}_{0}\right)$ and at the height where the concentration $\hat{C}$ decreases to one tenth of $\hat{C}_{0}$.

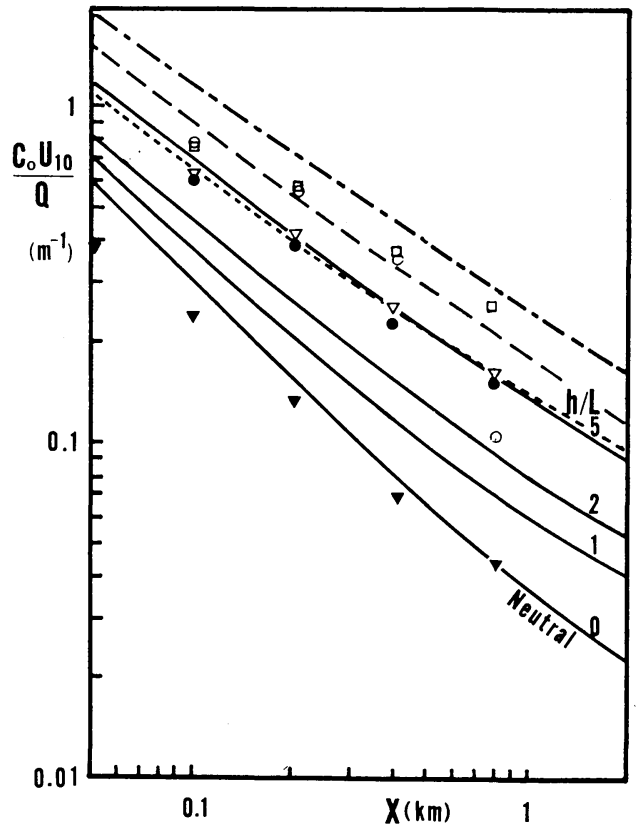

Fig. 17 The same as Fig. 16 except for $h<200 \mathrm{~m}$. Refer to case 2 in Table 3 .

$\begin{array}{rcl}h(m) & h / L & \text { Run No. } \\ --110 & 14 & 36(\bigcirc) \\ -60 & & 37(\nabla), 59(\nabla) \\ -.-.-25 & 15 & 14(\bigcirc) \\ \ldots \ldots \ldots . . .20 & 2.5 & 32(\square)\end{array}$

We estimate the shape factor $s$ using the relation

$$
2^{s}=\frac{\ln \left(\hat{C}\left(\hat{z}_{2}\right)\right)-\ln \left(\hat{C}\left(\hat{z}_{3}\right)\right)}{\ln \left(\hat{C}\left(\hat{z}_{1}\right)\right)-\ln \left(\hat{C}\left(\hat{z}_{2}\right)\right)}
$$

where $\hat{z}_{3}=2 \cdot \hat{z}_{2}=4 \cdot \hat{z}_{1}$ and $\hat{z}_{3}$ is chosen as $\hat{C}\left(\hat{z}_{3}\right)=$ $1 / 10 \cdot \hat{C_{0}}$. The shape factor $s$ of the concentration profiles in Fig. 18a to $\mathrm{c}$ are listed in Table 3. It is clear that in the mixing layer, the vertical profile of the short range diffusion is far from Gaussian and $s$ increases with $\hat{x}$.

Incidentally the distribution function is not given by a simple exponential power law. For instance, if we chose $\hat{z}$ as the height where $\hat{C}\left(\hat{z}_{3}\right)=$ $\hat{C}\left(\hat{Z}_{\sigma}\right)=0.6 \cdot \hat{C}_{0}$, instead of $\hat{C}\left(\hat{Z}_{3}\right)=0.1 \cdot \hat{C}_{0}$, the concentration distribution near the surface is emphasized and $s$ becomes much smaller (see Table 3). This tendency can be found in any type of stratificated layer.

In the neutral layer, $s$ is again less than 2 . Interestingly, the variation of $s$ with $\hat{x}$ is smaller than that in the mixing layer, at least over the distance investigated. The shape factor $s$ is also dependent on the roughness length. 
In the stable layer, we can expect the profile of the vertical concentration to have a roundish shape even near the source, since the diffusion in the upper part of the layer is strongly suppressed. In fact, the shape factor $s$ in the stable layer is as large as 1.7 over the short range of diffusion and increases beyond 2.0 at long downwind distances. With an increase of the stability $h / L, s$ also increases. Nieuwstadt and Ulden's

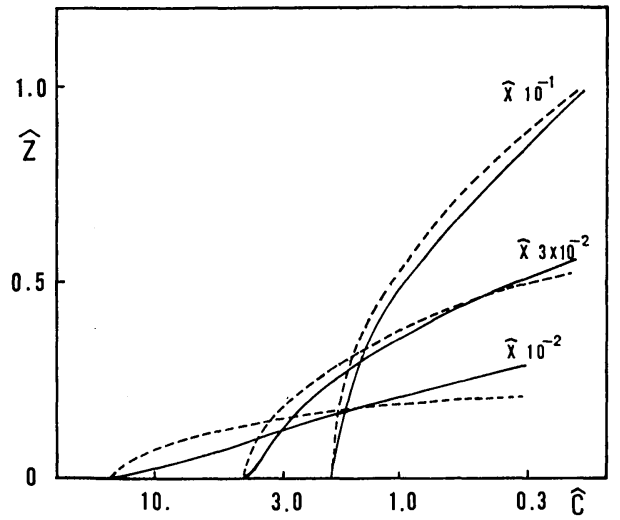

(a)

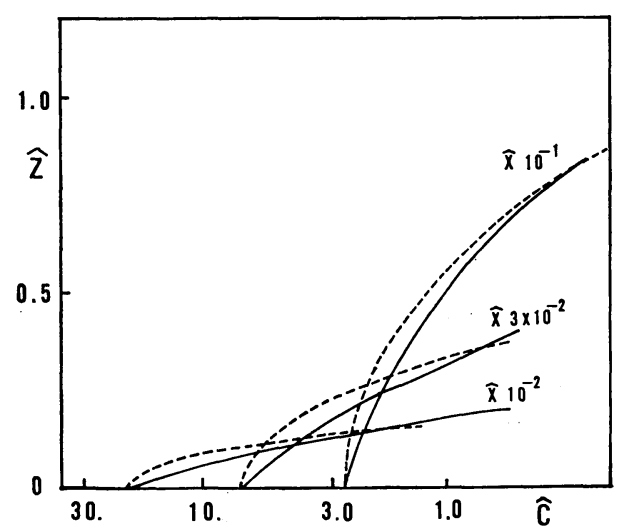

(b) result (1978) about the dependency of the shape factor $s$ on the stability is in qualitative agreement with our calculations. The dependency of $s$ on the downwind distance and the roughness length, however, has not been shown experimentally.

\section{Conclusions}

Vertical spread from a ground level source has been studied using Yokoyama et al.'s turbulent structure model $(1977 \mathrm{a}, \mathrm{b}, \mathrm{c})$. The characteristic vertical spread $Z_{\sigma}$ is, in general, written in the form

$$
\hat{Z}_{\sigma}=\frac{Z_{\sigma}}{h}=f\left(\frac{\alpha x}{R_{e} h}, \frac{z_{0}}{h}, \frac{h}{L}\right)
$$

where $h / L$ is necessary for the stable layer only.

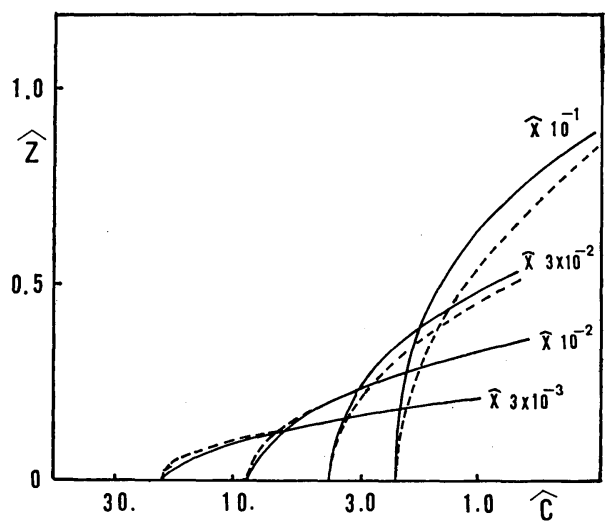

(c)

Fig. 18 Profiles of normalized vertical concentration for $\hat{z}_{0}=10^{-4}$. a) mixing layer, b) neutral layer, c) stable layer with $h / L=2$. Dashed lines are the Gaussian distribution functions which coincide with computed concentration at $z=0$ $\left(C=C_{0}\right)$ and the height where $C=$ $C_{0} / 10$.

Table 3 Values of the shape factor $s$

\begin{tabular}{r|c|cc|cc}
\hline & unstable & \multicolumn{2}{|c|}{ neutral } & \multicolumn{2}{|c}{ stable } \\
\hline \multicolumn{1}{c|}{$\hat{z}_{0}$} & $10^{-4}$ & $10^{-4}$ & $10^{-3}$ & \multicolumn{2}{|c}{$10^{-4}$} \\
\hline$\hat{X} h / L$ & & 0 & 0 & 2 & 5 \\
\hline $3 \times 10^{-3}$ & - & - & - & $1.7(1.3)$ & $2.2(2.1)$ \\
$10^{-2}$ & $1.0(0.9)$ & $1.1(1.0)$ & $1.2(1.2)$ & $2.0(1.5)$ & $2.5(2.2)$ \\
$3 \times 10^{-2}$ & $1.7(1.3)$ & $1.3(1.1)$ & $1.5(1.4)$ & $2.4(1.9)$ & - \\
$10^{-1}$ & $1.8(1.6)$ & $1.5(1.2)$ & $1.6(1.4)$ & $2.7(2.4)$ & - \\
\hline
\end{tabular}

Values in parentheses are obtained using the concentration profile under the height of the characteristic vertical spread $Z \sigma$. 
Substituting the specific variables into $R e$, we may infer qualitative features of the vertical diffusion. For instance, it appears that $Z_{\sigma}$ in the mixing layer depends on the traveling time of the plume, whereas in the neutral or the stable layer, $Z_{\sigma}$ becomes a function of downwind distance. Some characteristics of the results are as follows.

In the mixing layer, $Z_{\sigma}$ increases rather rapidly over the short range where the turbulence in the surface layer dominates the diffusion. But when $Z_{\sigma}$ increases and the turbulence in the upper part of the layer becomes dominant, the development of $Z_{\sigma}$ begins to slow down. In connection with this phenomenon, the concentration in the early stages of diffusion decreases very sharply up from the surface and at long downwind disstance, the profile approaches a Gaussian distribution.

In the neutral layer, the roughness length of the surface is effective in the development of vertical spread. In the stable layer, since the eddy diffusivity in upper part of the layer decreases with an increase of $h / L$, the diffusion in the upper part of the stable layer. may be strongly suppressed and the profile of the vertical concentration becomes rounded even at short distances. The development of $Z_{\sigma}$ near the source is, however, governed mostly by the roughness of the surface as in the neutral layer. The effect of $h / L$ becomes dominant with increasing downwind distance.

Results of the numerical calculations agree with experiments if the eddy diffusivity of material is assumed to be approximately $2 \cdot K_{m}$ in the unstable layer and $1.55 \cdot K_{m}$ in the near-neutral to stable layers.

The shape factor $s$ defined by equation (35) is not uniquely determined in any of the stratifications. It increases with the downwind distance and the vertical extent which is taken into account to estimate $s$ itself. In addition it depends on the stability of the layer and the roughness of the surface.

\section{References}

Barad, M. L., 1958: Project Prairie Grass, a field program in diffusion. AFCRL-TR-58-235 (3 volumes).

Businger, J. A., J. C. Wyngaard, Y. Izumi, and E. F. Bradley, 1971: Flux-profile relationships in the atmospheric surface layer. J. Atmos. Sci., 28, 181-189.

Chaudhry, F. H., and R. N. Meroney, 1973: Simi- larity theory of diffusion and the observed vertical spread in the diabatic surface layer. BoundaryLayer Meteor. 3, 405-415.

Deardorff, J. W., and G. E. Willis, 1975: A parameterization of diffusion into the mixed layer. J. Appl. Meteor., 14, 1451-1458.

Gamo, M., O. Yokoyama, S. Yamamoto, and Y. Mitsuta, 1976: Structure of the atmospheric boundary layer derived from airborne measurements of the energy dissipation rate $\_$. J. Meteor. Soc. Japan, 54, 241-258.

- -1979 : Growth of the depth and the diurnal variation of vertical profiles of temperature and turbulence characteristics in the mixing layer. J. Meteor. Soc. Japan, 57, 159-172.

Horst, T. W., 1979: Lagrangian similarity modeling of vertical diffusion from a ground level source. J. Appl. Meteor., 18, 733-740.

McElroy, J. L. and F. Pooler, 1968: St. Lcuis dispersion study, Vol. II-Analysis, National Air Pollution Control Administration, Arlington, Va., Pub. No. AP-53.

Mizuno, T., O. Yokoyama, and A. Yasuraoka, 1980: On the somke plume width in the atmospheric boundary layer (part 2). Bull. Nat. Res. Inst. Poll. \& Res. 10, 51-61. (In Japanese).

Monin, A. S., and A. M. Yaglom, 1971: Statistical Fluid Mechanics; Mechanics of Turbulence, Nauka Press, Moscow.

Nieuwstadt, F. T. M., 1979: Application of mixedlayer similarity to observed dispersion from a ground level source. J. Appl. Meteor., 19, 157162 .

-, and A.P. Ulden, 1978: A numerical study on the vertical dispersion of passive contaminants from a continuous source in the atmospheric surface layer. Atmos. Environ., 12, 21192124.

Panofsky, H. A., 1974: The atmospheric boundary layer below 150 meters. Annual review of fluid mechanics, 6, 147-177.

Pasquill, F., 1974: Atmospheric Diffusion. John Willey, New York.

Webb, T.K., 1970: Profile relationships: The loglinear range and extension to strong stability. Quart. J. Roy. Meteor. Soc., 96, 67-90.

Yamamoto, S., O. Yokoyama, and M. Gamo, 1979: Observational study on the turbulent structure of the atmcspheric boundary layer under stable conditions. J. Meteor. Soc. Japan, 57, 423-432.

Yokoyama, O., M. Gamo, and S. Yamamoto, 1977a: On the turbulence quantities in the atmospheric mixing layer. J. Meteor. Soc. Japan, 55, 182-192.

bulence quantities in the neutral atmospheric boundary layer. J. Meteor. Soc. Japan, 55, 312318. 
the vertical profiles of wind velocity in the atmospheric boundary layer. Bull. Nat. Res. Inst. Poll. \& Res., 7, 1-7. and T. Mizuno, 1978: An aspect on the smoke plume width in the atmospheric boundary layers. Kōgai, 13, 257-262. (In Japanese)

\title{
大気境界層中における地上煙源からの鉛直拡散について
}

\author{
水 野 建 樹・横 山長之 \\ 公害資源研究所
}

\section{安楽岡顕}

数理 計画

大気境界層に関する横山らの乱流構造モデルを用いて拡散の微分方程式を解き, 地上煙源からの鉛直拡散につ いて調べた。方程式を無次元することにより，代表的な鉛直拡散幅（Zoで表わす）を境界層の高さ $(h)$ で割っ た值 $(Z \sigma / h)$ は混合層, 中立層のとき $X / R_{e} h\left(X:\right.$ 煙源からの風下距離, $R_{e}$ : 拡散係数と風速拉よび高さについ ての代表値を組み合わせてできる無次元パラメータ）と $z_{0} / h\left(z_{0}\right.$ : 地表面粗度長) で表わされることが導びかれ る。安定層ではさらに $h / L(L:$ Monin Obukhov 長さ) がもら一つの無次元パラメータになる。この結果を用 いると混合層中の鈶直方向払散幅は煙の輸送時間に依存し, 中立層, 安定層では風下距離だけの関数となること がわかる。

計算した結果について特徵的なことは, 混合層では拡散初期のころ, Z $\sigma$ が急激に增加し後にゆるやかに增加 するようになる。中立層, 安定層ではこのような顕著な変化は認められない。また, 混合層での濃度分布形は拡 散初期に指数分布に近く，次第にガウス分布に近づくのに対し，安定層でははじめから既にガウス分布に近く， 拡散するにつれて，益々丸みを扣びた形になる。

モデルの妥当性は大気中に搢ける拡散実験および Pasquill-Gifford 線図と比較することにより検討した。 